\title{
USE OF PENOTRANE IN OPHTHALMOLOGY* TREATMENT OF RECURRENT STAPHYLOCOCCAL LESIONS AND BLEPHARO-CONJUNCTIVITIS
}

\author{
BY \\ BRUCE JACKSON \\ Manchester Royal Eye Hospital
}

IN the treatment of chronic staphylococcal blepharo-conjunctivitis and of recurrent styes experience has shown that there has been a chemotherapeutic hiatus between conventional therapy with antibiotics and recourse to staphylococcal vaccines, which provide a time-consuming, though frequently effective, treatment.

The claims made for a number of antiseptics were therefore considered, and it was felt that the reported properties of phenylmercuric dinaphthylmethane disulphonate (hydrargaphen; Penotrane) would be worth examining.

Penotrane, in addition to activity against Gram-positive and Gram-negative bacteria, has powerful activity against pathogenic fungi (Goldberg, Shapero, and Wilder, $1950 \mathrm{a}$ and $\mathrm{b}$; Haler, 1957; Tiessen, 1957). It penetrates living tissue, and is therefore effective in the region of the hair follicles of the lashes (Goldberg and others, $1950 \mathrm{~b}$ ). It is colourless and non-staining-virtually essential requirements for topical use in the eye. It is not a substance against which bacterial resistance develops, and it does not appear to give rise to skin sensitivity, such as may be encountered with the antibiotics (Tiessen, 1957).

\section{Material and Methods}

Since Penotrane had not previously been used topically in the eye some studies were carried out, first in experimental animals and then in human volunteer subjects, which showed the compound to be well tolerated by the eye in a concentration of 0.033 per cent. and free from immediate toxic effects.

Octrane Lotion.-Different preparations of Penotrane were examined for their suitability in particular lid and eye infections, the first clinical studies being concerned with the use of the antiseptic in a detergent formulation for toilet of the lids in chronic blepharitis and removal of the strongly adherent crusts of dried exudate. The detergents tried were, in succession, triethanolamine lauryl sulphate, Tween 80 , and Lissapol. In the concentrations used, the first of these produced a heavy deposit (probably of metallic mercury) soon after preparation of the lotion. Tween 80 also caused some deposit, but this formed more

\footnotetext{
* Received for publication October 9, 1964.
} 
slowly over a period of days, so that the freshly prepared Penotrane-Tween 80 solution was satisfactory, and has caused no trouble in clinical use. Lissapol proved to be the most satisfactory of the three detergents, and a stable Lissapol-Penotrane solution is now obtainable under the name Octrane lotion (containing 0.033 per cent. Penotrane).

In the early stages of the investigation it became apparent that in spite of the success of the lotion another preparation possessing more prolonged action would prove advantageous.

Octrane Gel.-The base chosen was hydroxyethyl cellulose, the $p \mathrm{H}$ being adjusted to neutrality; the strength of Penotrane was kept at 0.033 per cent. The consistency of the preparation was that of an easily applied viscous eye drop. The gel is stable, but is liable to dehydration and solidification if the cap of the tube is not screwed on firmly after use.

Frequency of Application.-The lotion was applied on a pledget of cotton wool 6-hourly; if used solely for the removal of crusts in addition to the Octrane gel, it was only used as required. The Octrane gel was used three times daily at first, later reducing to twice a day and eventually to a single application before going to sleep at night.

Additional Measures.-In addition to an explanation of the necessity for either the initiation or overhaul of personal and family hygiene (for example, the provision of individual towels for members of a family) where staphylococcal reservoirs in the anterior nares were shown to be present, patients were treated with an antibiotic ointment containing either neomycin and bacitracin or chloramphenicol. However, the complications of issuing the correct ointment and the other reasons for the preference for non-sensitizing antiseptics soon led to the use of Penotrane jelly 1 per cent. for the control of staphylococci in the anterior nares. The patients were instructed to introduce a little of the jelly into each nostril twice daily with the little finger, drawing it across the nostril, and on no account allowing the nail into the nostril, thus causing possible injury leading to staphylococcal penetration.

Clinical Material.-The patients treated have all been referred after failing to respond to conventional treatment at the Manchester Royal Eye Hospital. Many have presented a long-standing picture of intractable or recurring infection. The referred patients were often accompanied by a request for the preparation of an autogenous vaccine, but only in two cases was such a course eventually necessary. Conversely, one patient who had received a course of vaccine without lasting effect found that the Octrane lotion controlled the condition admirably.

The majority of the cases were of chronic staphylococcal infections manifested as recurrent styes, blepharitis, or conjunctivitis, or a combination of these conditions. The remainder consisted of a miscellaneous group which included two cases of staphylococcal infection following operations for squint which had failed to respond to antibiotics, one long-standing case of antibiotic-resistant Proteus infection after a scleral resection, one discharging socket, and two cases of chalazion (Table I).

TABLE I

INFECTIONS IN 52 CASES TREATED With Penotrane

\begin{tabular}{|c|c|}
\hline Disease & $\begin{array}{l}\text { No. of } \\
\text { Cases }\end{array}$ \\
\hline $\begin{array}{l}\text { Recurrent styes } \\
\text { Blepharitis } \\
\text { Blepharo-conjunctivitis } \\
\text { Chronic conjunctivitis } \\
\text { Infected socket } \\
\text { Staphylococcal infection following } \\
\text { operation for squint } \\
\text { Proteus infection after scleral } \\
\text { resection }\end{array}$ & $\begin{array}{r}25 \\
12 \\
3 \\
8 \\
1 \\
2 \\
1\end{array}$ \\
\hline Total & 52 \\
\hline
\end{tabular}


TABLE II

Results of 52 Cases treated with Penotrane

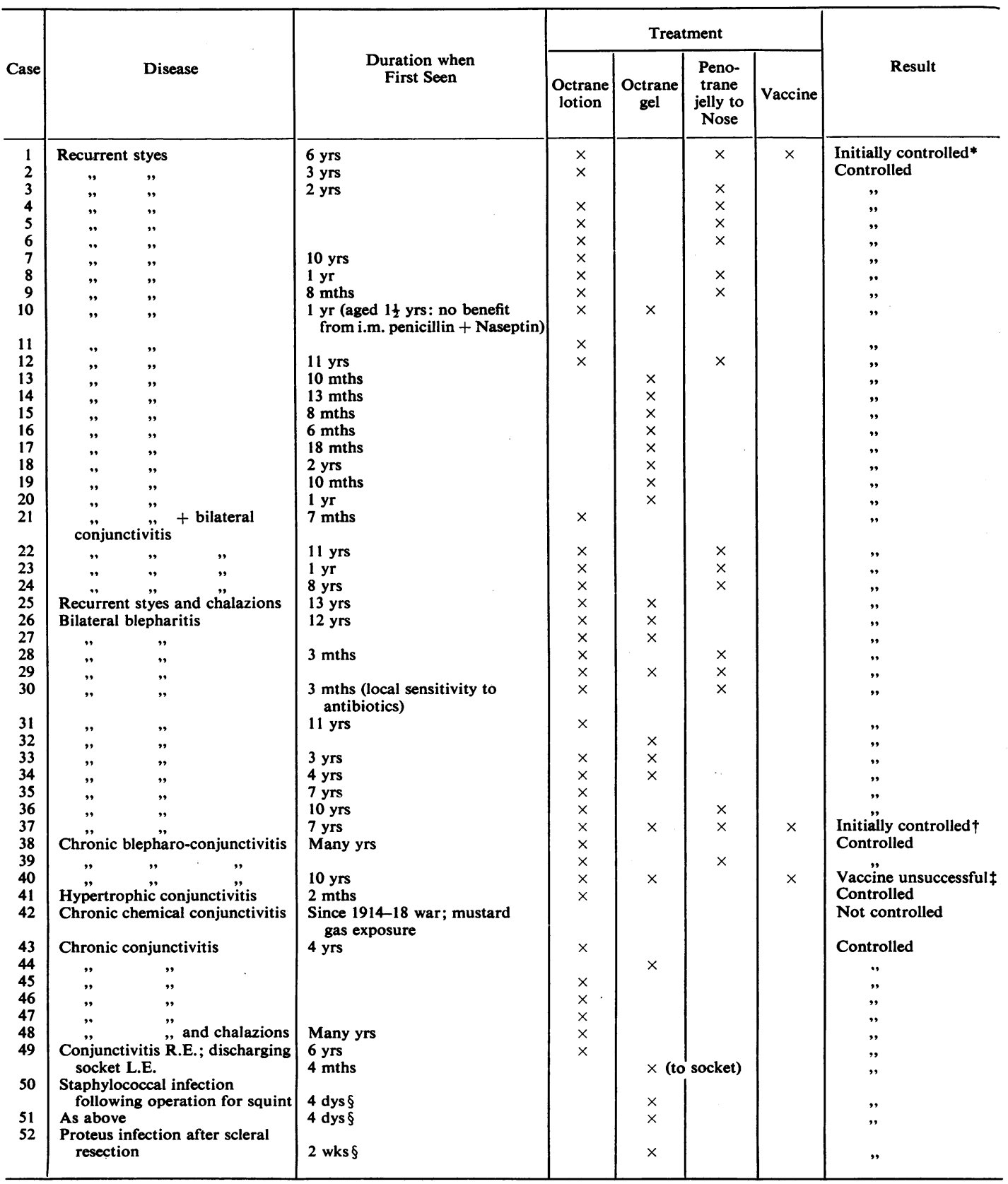

* Initially controlled with Octrane but vaccine given later with success.

† Initially controlled; later vaccine therapy produced some improvement but relapses frequent.

$\ddagger$ Vaccine unsuccessful. Octrane gel too astringent; controlled with Octrane lotion.

$\S$ In these cases a pathogenic organism had been isolated and its sensitivity to antibiotics tested, but the application of the appropriate antibiotic had not influenced the course of the infection. 


\section{Results}

There were only three failures: one was in a patient with epithelial damage resulting from exposure to mustard gas in the First World War and two in patients who obtained initial benefit, but recurrence of the condition prompted the use of a vaccine. From the presentation of the results in tabular form (Table II) one cannot obtain the picture of relief which most patients expressed.

In some cases it has been found necessary to continue the use of Octrane gel over long periods. Where the condition has been present for many years it appears that it may be necessary to continue treatment for years to come, especially because of the variability in the condition. This does not seem to distress the patient, who finds he is able to obtain relief which he had never experienced before.

Side-effects.-A close watch was kept for the drawbacks which may be associated with active useful drugs and preparations, in particular, evidence of erethism or mercurialentis, both of which have been reported as effects of prolonged exposure to mercury (Burn, 1962). Neither of these effects has been observed despite prolonged application of Octrane gel-for as long as thirty-four months in one patient who is still using one application nightly to control her chronic blepharitis.

Another possible hazard of using mercury is the causation of pink disease in infants. Systemic absorption of mercury following external application of Penotrane has been shown to be negligible, and no reports of suspected pink disease in infants treated locally with Conotrane (Penotrane-silicone) for napkin eruptions have been received by the company marketing Penotrane. Nevertheless, it may be a wise policy to use Penotrane in the eyes of infants only when other treatment has been tried without success. We have used this antiseptic (in the form of Octrane gel) for only one baby, a case of recurrent styes which had failed to respond to intramuscular penicillin and local antibiotics to the lids and anterior nares.

The only local side-effect noted in all patients has been a tolerable astringent stinging after application of Octrane lotion and Octrane gel. After two or three days' regular application this side-effect becomes less marked and ceases to trouble the patients.

\section{Conclusion}

Octrane gel, alone or in combination with Octrane lotion or Penotrane jelly, has controlled infections of the lids or conjunctivae in 51 out of 52 chronic, recurrent, or intractable cases. Octrane has been found to be most helpful in the treatment of recurrent styes, staphylococcal blepharo-conjunctivitis, and other superficial pyogenic infections of the eye and lids.

\section{Summary}

Fifty-two patients suffering from chronic superficial pyogenic bacterial infections (51 staphylococcal and 1 Proteus) of the eye and eyelids were treated by local applications of phenylmercuric dinaphthylmethane disulphonate (hydrargaphen; Penotrane) in the form of Octrane gel or Octrane lotion. In most of the cases of 
recurrent styes and blepharitis Penotrane jelly was applied to the anterior nares as an additional therapeutic measure. All the cases were resistant to previous treatment. In all but one of the cases (a chronic chemical conjunctivitis due to mustard gas exposure) the infection was controlled by Octrane; in two cases which responded initially vaccines were later used.

I should like to express my thanks to the consultant ophthalmic surgeons at Manchester Royal Eye Hospital for referring their patients to me, and to Mr. W. Chatterton, Chief Pharmacist, for his help.

The Octrane gel and lotion, the Penotrane for the Penotrane-Tween 80 application, and the Penotrane jelly (1 per cent.) were supplied for this study by Ward, Blenkinsop \& Co. Ltd.

\section{REFERENCES}

BURN, R. A. (1962). Proc. roy. Soc. Med., 55, 322.

Goldberg, A. A., Shapero, M., and Wilder, E. (1950a). J. Pharm. Pharmacol., 2, 20. $\longrightarrow,-$, (1950b). Ibid., 2, 89.

HALER, D. (1957). Antibiot. Med., Brit. ed., $2,358$.

Tiessen, H. J. (1957). Derm. Wschr., 135, 548. 